\title{
Patterns of Response to Global Threats and Opportunities
}

\author{
Jehiel Zif ${ }^{1}$ \\ ${ }^{1}$ Hult International Business School, USA; Faculty of Management, Tel-Aviv University, Tel Aviv, Israel \\ Correspondence: Jehiel Zif, Professor of Business Administration, Hult International Business School, USA.
}

Received: December 30, 2015

Accepted: January 14, 2016

Online Published: January 26, 2016

doi:10.5430/jms.v7n1p37

URL: http://dx.doi.org/10.5430/jms.v7n1p37

\begin{abstract}
Response to global threats and opportunities is examined on the basis of three behavioral variables: 1. Trigger identification of an environmental reason for change, 2. Response time to prepare for implementing a change, and 3. Newness in the content of response. The paper explores the correlations among these variables and their impact on the successful treatment of threats and opportunities. Differences of response to threats versus opportunities show a higher change readiness in dealing with opportunities than with threats. These differences are affected by the orientation, or strategy of the organization - external or internal. The data for the exploratory study is based on questionnaires from managers of eighty international organizations.
\end{abstract}

Keywords: change, readiness, threats, opportunities, trigger identification

\section{Introduction}

Organizational success is greatly influenced by the way it responds to environmental changes. In this paper we explore the relationship between perceived threats and opportunities and organizational response according to a model of three behavioral variables, which can be called change readiness. In addition, we study the influence of organizational orientation and strategy on the patterns of response. This exploratory study can make some contribution to a better understanding of the response patterns, raise questions for further research and influence managerial thinking.

The paper has five parts:

1) Presentation and discussion of the response variables.

2) Research hypotheses.

3) Methodology.

4) Analysis and discussion of findings.

5) Conclusion and implications.

The data for the study is based on questionnaires from eighty managers of organizations from fifteen countries. The study takes the the point of view of an independent organization, or a strategic business unit within a conglomerate organization.

\section{Patterns of Response}

The three variables of response which are discussed below have to do with the organizational propensity to deviate from managerial inertia. (Ansoff 1984, Aaker and Mascarenhas 1984. Timmor and Zif 2010). They are designed to capture the demonstrated capacity of an organization to respond effectively to important new developments in its business environment. The following variables are based on behavior rather than on attitude.

1) Identification time of an environmental trigger for change.

2) Response time to prepare for implementing a change.

3) Newness in the content of response.

A variation of these variables has been discussed in the literature. 
Ansoff has made a strong case for distinguishing between alternative response patterns based on two variables: 1). Early versus late identification of the need for change, and 2). The rate of preparation for implementing a change (Ansoff 1984).

Mitroff emphasized the distinction between revolutionary change which requires a new pattern of response by the organization, and an evolutionary change which the organization can handle without changing existing values (Mitroff 1988)

Timmor and Zif have studied the conceptualization of the three variables of change readiness and their relationship with external and internal organizational variables. The study did not distinguish between opportunities and threats.

1). Identification time of an environmental trigger for change. An identification of an environmental trigger with a likely strategic impact on the firm is considered here a key for action. By strategic impact is meant serious implications with long-term consequences.

What is meant by these triggers?

One basic classification distinguishes between threats and opportunities. While it is true that in many cases a threat can be viewed as an opportunity and vice versa, most organizations tend to identify environmental signals either as threats, or as opportunities, and the strategic literature frequently classifies outside events into threats or opportunities (Ansoff 1954, Urban 1991).

The triggers can also be identified based on their origin. Typical origins include:

---A shift in consumer demand.

---A technological development.

---A change in governmental regulations or policies.

---A change in competitive activity.

Early identification of meaningful triggers is usually very valuable in preparing for strategic changes. Substantial time is usually needed to prepare properly without last minute panic. There is also a higher probability that the "window of opportunity" will not be missed. The above examples of possible threats and opportunities were presented in the questionnaire, but interviewees were not asked to identify or classify the chosen global threat and opportunity. Other studies have concentrated on organizational action in response to different kinds of threats and opportunities. (Chattopadhyay, Glick and Uber 2001)

2). Response time to prepare for implementing a change.

Recognizing a need, or an opportunity, is a necessary but insufficient condition for undertaking strategic change. The second variable deals therefore, with the time it takes to respond. This variable is not completely independent from the first one. If the organization is very slow in identifying an environmental threat, the time available for preparing action might be quite short.

One could think of two separate stages of response time. The first is the time until the organization begins to prepare a response and the second is the time that this preparation takes.

For statistical comparisons across companies, the preparation time is a difficult variable for two reasons, first because it is content-related and second because preparation could be regarded as an ongoing continuing activity. A measure which views "early versus late start of action preparation" could better represent the response time to prepare for implementing a change.

It has been argued that the speed, with which one moves to translate trigger identification for action, is the most critical component for successful strategic change. (Kotter, 2008)

3). Newness in the content of response.

The third variable deals with the content of response rather than its timing. One can envision a continuum of possible responses between an incremental, familiar action, and a revolutionary change. An organization which is capable of undertaking a revolutionary response is assumed to have a higher degree of change readiness. This of course does not mean that a revolutionary response is always desirable. A major deviation from past behavior is more likely to be needed when the outside threat or opportunity have a high potential impact on the firm. In this study, respondents were asked to select "strategic" threats and opportunities, which have implications for high impact.

Evolutionary changes have a low degree of newness. They do not require changes in basic values or a major shift in managerial behavior. The response pattern has been tried before and is therefore familiar to the firm. Limited 
deviation from organizational inertia is required. Revolutionary changes are based on a new pattern of response. Such changes have to overcome a natural resistance both inside and outside the organization. A strong, committed leadership is usually needed to implement action which is completely new to the organization and its affiliates. There are of course many intermediate situations, where the organization has been experimenting with an innovative approach on a small scale, prior to its adoption on a large scale.

\section{Research Hypotheses}

H1. The three response variables - early identification of signals, early start, and the innovative content of action are moderately correlated with each other.

This hypothesis, if confirmed, would suggest that the pattern of organizational response can be viewed as one integrative factor rather than as three totally independent variables. It would also mean than organizations could be clustered into groups by their level of response. The expectation for a moderate degree of correlation suggests that even though the variables are correlated, each has its own separate content.

H2. Successful treatment of threats and opportunities is positively associated with a high score on the three response variables.

There is a built-in assumption that quick and innovative response is a good thing which is contributing to success. This assumption deserves testing.

One can question whether innovative action is already a measure of success. But innovative action is not always needed for success and it is also a risky process witch does not guarantee success.

H3. Organizations tend to have a higher change readiness toward opportunity signals rather than toward threat signals. Opportunities are more exciting and optimistic while threats are possibly riskier and are associated with a failure mentality. It is therefore hypothesized that as a result many managers prefer to concentrate on opportunities.

Tversky and Kahanman (1979) have demonstrated that people in normal circumstances are more concerned with negative than positive developments. The implications might be that change readiness for threats would be on a higher level than for opportunities. But in this study we look at organizations and not individuals. We assume that managers prefer to delay dealing with threats because they don't want to be the messenger with bad news. We did not find in the literature a reference to the speed of response to threats versus opportunities.

H4. The difference in response to threats and opportunities can be related to organizational orientation and strategy. An organization which is externally oriented, with expansion ambitions, is more likely to concentrate on opportunities rather than threats. An organization which is internally oriented with a defensive strategy is more likely to concentrate on threats.

It seems reasonable to assume that how an organization responds to different triggers will be affected by its strategy and orientation. Variables associated with an externally oriented organization are: active marketing (indicated by commitment of resources and marketing orientation), market share, and product/ market breadth. Variables associated with an internal and defensive orientation are operational efficiency, profitability and size of the organization (relative to the industry). Is is hereby assumed that a large organization with high profitability is more likely to be concerned in protecting its position than with exploring expansion opportunities.

\section{Methodology}

The data that were used to test the hypotheses were drawn from an exploratory survey of 80 executives from 15 countries.

The survey instrument was a questionnaire structured in a consistent form. The responses to all questions with the exception of the classification data, were recorded on a scale from 0 to 100. Most questions were based on a comparison with the industry average of the respondent organization --- a score of 50 (See Table 1). The questionnaire had three parts:

Part one had 8 questions, four about the organization's response and success in dealing with a specific recent strategic threat and four similar questions about a recent strategic opportunity. Examples of relevant environmental threats and opportunities, similar to those presented in section two of this paper, were provided.

Part two of the questionnaire was adapted with minor modifications from (Segev and Gray 1990). This part had 28 questions dealing with the environment, strategy content, strategy making process, structure, performance, age and size. 
Part three had 7 classification questions about the respondents, their organizations and their international activities. In this part respondents were asked to classify the source of their environmental triggers between domestic and global.

Quantification of the responses assumed interval scale. An acceptable response had to be complete and be given by an executive of an organization which marketed a product or a service.

The questionnaires were administered in the following situations: (a) 28 responses were from overseas managers attending the Public Enterprise Workshop of the Harvard Institute of International Development: (b) 30 responses were from full time managers in the High Tech MBA program of Northeastern University. (c) The other responses were collected from managers in a variety of settings as a byproduct of consulting, training, or other graduate courses.

Respondents in this survey have been classified as follows: $28 \%$ senior managers, $35 \%$ middle managers and $37 \%$ other staff functions;

About half of the firms in the sample are based outside the United States; $34 \%$ of the respondents come from state-owned enterprises, $31 \%$ public enterprises, and $35 \%$ private. Classification by activity show $42 \%$. service organizations, $48 \%$, manufacturing with about half in high-tech industries, and $10 \%$. in product companies without manufacturing. $97 \%$ of the firms in the survey are involved with export activity.

Table 1a. List of variables

\begin{tabular}{|c|c|c|}
\hline CONCEPT (NAME) & OPERATIONALIZATION & SCALE \\
\hline \multicolumn{3}{|c|}{ VARIABLES OF RESPONSE AND SUCCESS } \\
\hline Identification & Organization Identified this $\mathrm{T} / \mathrm{O}$ at the: & $\begin{array}{l}\text { Earliest possible time (100); very } \\
\text { late }(0)\end{array}$ \\
\hline Start Preparation & $\begin{array}{l}\text { Organization start preparing to deal } \\
\text { with this } \mathrm{T} / \mathrm{O} \text { : }\end{array}$ & $\begin{array}{l}\text { Immediately }(100) \text { When there } \\
\text { was no choice }(0)\end{array}$ \\
\hline Innovative Action & Organization took: & $\begin{array}{l}\text { Incremental, familiar action }(0) \\
\text { Innovative response }(100)\end{array}$ \\
\hline Success & Rate the success In dealing with & Highest rate (100) Failure (0) \\
\hline
\end{tabular}

Table 1b. List of variables

\begin{tabular}{|c|c|c|}
\hline CONCEPT (NAME) & OPERATIONALIZATION & SCALE \\
\hline \multicolumn{3}{|c|}{ VARIABLES OF ORGANIZATIONAL ORIENTATION AND STRATEGY } \\
\hline \multirow[t]{2}{*}{ Product/market Breadth } & Relative number of products and & Highest in industry (100) \\
\hline & Customers & Average (50) \\
\hline \multirow[t]{2}{*}{ Active marketing } & Orientation and resources allocated & Highest possible(100) \\
\hline & to marketing & Industry average (50) \\
\hline \multirow[t]{2}{*}{ Market share } & Relevant market Share & Monopoly (100) \\
\hline & & Relative sales. \\
\hline \multirow[t]{2}{*}{ Profitability } & Return on equity & Most profitable(100) \\
\hline & & Industry average(50) \\
\hline \multirow[t]{2}{*}{ Operational Efficiency } & Production relative to Resources & Most efficient(100) \\
\hline & & Industry average(50) \\
\hline \multirow[t]{2}{*}{ Size } & Sales-assets employees relative to & Largest (100) \\
\hline & industry & Industry average(50) \\
\hline
\end{tabular}




\section{Empirical Findings}

\subsection{Correlation Analysis}

The first analysis examined simple inter-correlations between six response variables, three for threats and three for opportunities. The correlations with the two success variables are shown as well. (See Table 2).

Eleven out of fifteen inter-correlations between the response variables hypothesized in $\mathrm{H} 1$ are significant at the 1\% level. Two are significant at the 5\% level and two are non-significant. The two non-significant correlations are the two innovative action variables with the two identification variables. Correlations values for the change readiness variables dealing with threats range from .34 to .52 and for the opportunity variables .29 to .69 . These could be considered moderate correlations.

All the CR variables are correlated significantly with the two success variables dealing with threats and with opportunities. These finding support $\mathrm{H} 2$.

Table 2. Correlations between Change Readiness variables and Success variables

\begin{tabular}{|c|c|c|c|c|c|c|c|c|}
\hline & $\mathbf{X 1}$ & $\mathbf{X 2}$ & $\mathbf{X 3}$ & $\mathrm{X} 4$ & $\mathbf{X 5}$ & X6 & $\mathbf{X 7}$ & $\mathbf{X 8}$ \\
\hline \multicolumn{9}{|c|}{ CHANGE READINESS VARIABLES THREAT } \\
\hline Xl. Identification & 1.00 & & & & & & & \\
\hline X2. Start preparation & $.51 *$ & 1.00 & & & & & & \\
\hline $\begin{array}{l}\text { X3. Innovative } \\
\text { action }\end{array}$ & $.34 *$ & $.52 *$ & 1.00 & & & & & \\
\hline \multicolumn{9}{|l|}{ OPPORTUNITY } \\
\hline X4. Identification & $.49^{*}$ & $.45^{*}$ & $.15 \mathrm{a}$ & 1.00 & & & & \\
\hline X5. Start preparation & $.34^{*}$ & $.47^{*}$ & $.19^{*}$ & $.69^{*}$ & 1.00 & & & \\
\hline $\begin{array}{l}\text { X6. Innovative } \\
\text { action }\end{array}$ & $.17 \mathrm{a}$ & $.28^{*}$ & $.13 b$ & $.29 *$ & $.51^{*}$ & 1.00 & & \\
\hline \multicolumn{9}{|l|}{ SUCCESS } \\
\hline X7. With threat & $.37 *$ & $.67^{*}$ & $.51^{*}$ & $.26^{*}$ & $.33^{*}$ & $.37^{*}$ & 1.00 & \\
\hline X8. With opportunity & $.34^{*}$ & $.35^{*}$ & $.32 *$ & $.37 *$ & $.54^{*}$ & $.54^{*}$ & $.51 *$ & 1.00 \\
\hline
\end{tabular}

$\mathrm{N}=80$ cases

*Significant at the .01 level

a Significant at the .10 level

b Not significant

\subsection{Regression Analysis}

A multiple regression analysis of the success variables is presented in Table 3 . The independent variables are the three CR variables, where threats and opportunities are treated separately. The regressions are significant at the $1 \%$. level with an R square of .51 for the threat regression and .38 for the opportunity regression. In each regression, one variable is probably not significant due to the inter-correlations with the other independent variables. These findings support $\mathrm{H} 2$.

It is interesting to note that the prediction of success in the regression equation is based on two distinct change readiness variables of preparation time and newness in the content of response. 
Table 3. Regression Analysis of Success with Threats and Opportunities by Change Readiness variables

\begin{tabular}{lll}
\hline EXPLANATORYVARIABLES & THREAT & OPPORTUNITY \\
CHANGE READINESS & \\
\hline THREAT &
\end{tabular}

1. Identification

.101

2. Start preparation

3. Innovative action

$2.69^{*}$

\section{OPPORTUNITY}

$\begin{array}{lll}\text { 4. Identification } & & , 314 \\ 5 . \quad \text { Start preparation } & & 2.33^{*} \\ \text { 6. Innovative action } & & 3.42^{*} \\ \text { Constant } & 4.32^{*} & 1.84^{* *} \\ \text { R Square } & .51 & .38 \\ \text { F } & 26.2 & 15.7 \\ \text { S } & .000 & .000\end{array}$

$\mathrm{N}=80$ cases

*Coefficients are significant at the .01 level

** Coefficients are significant at the .05 level

\subsection{Analysis of Mean Score Response to Threats versus Opportunities}

This comparison is presented in Table 4 . The table shows that on each of the three variables of change readiness, the response to opportunities is higher than the response to threats. Trigger Identification and preparation time are performed earlier and the response is considered more innovative. All differences of the response variables are significant, thus supporting $\mathrm{H} 3$.

The difference in the assessment of success in dealing with opportunities is slightly higher than with threats, but it is not significant with the present size of the sample.

Table 4. Analysis of Mean Score differences in Response variables by Threats and Opportunities

\begin{tabular}{llll}
\hline $\begin{array}{l}\text { CHANGE READINESS } \\
\text { VARIABLES }\end{array}$ & THREATS & OPPORTUNITIES & SIG. \\
\hline 1. IDENTIFICATION & 53.5 & 69.2 & $*$ \\
& $(27.8)$ & $(25.3)$ & \\
2. START PREPARATION & 54.6 & 68.6 & $*$ \\
& $(30.5)$ & $(25.4)$ & $*$ \\
3. INNOVATIVE ACTION & 49.0 & 57.2 & \\
& $(28.3)$ & $(28.7)$ & \\
4. SUCCESS & 55.4 & 58.0 & \\
& $(24.1)$ & $(25.9)$ & \\
\hline
\end{tabular}

$\mathrm{N}=80$ cases

*Significant difference at the .05 level

Numbers in parentheses are standard deviations. 


\subsection{Correlations of Response to Threats and Opportunities by Organizational Orientation (see Table 5)}

In order to generate table 5 the three variables of response were grouped together, separately for threat response and opportunity response. By this grouping we can view the combined effect of the three variables. The significant correlations between the response variable of each group in Table 1 support the notion that these variables can be grouped.

The analysis supports the hypothesis that organizations with external and aggressive orientation, as indicated by product/market breadth, active marketing and market share have a higher and significant correlation with opportunities than with threats.

Organizations with an internal and defensive orientation as indicated by strong operational efficiency, profitability and size have a higher correlation with threat response. This finding tend to support $\mathrm{H} 4$.

It is important to note that the interpretation of the organizational orientation is implied rather than measured directly.

Table 5. Correlations of Response to Threats and Oportunities by Organizational Orientation

\begin{tabular}{lll}
\hline ORGANIZATIONAL VARIABLES & OPPORTUNITY RESPONSE & THREAT RESPONSE \\
EXTERNAL ORIENTATION & & .12 \\
\hline Product/market breadth & $.24^{*}$ & .13 \\
Active marketing & $.35^{*}$ & .08 \\
Market share & $.19^{*}$ & $.31^{*}$ \\
INTERNAL ORIENTATION & & $.26^{*}$ \\
Operational efficiency & .14 & $.16^{* *}$ \\
Profitability & .09 & \\
Relative Size & .03 & \\
$=80$ & & \\
Significant at the .01 level & &
\end{tabular}

\section{Discussion}

Successful response to environmental shifts was found to be strongly associated with three separate, but related activities: Early identification of the need to act, quick mobilization for action and novelty in the content of response (Tables 2 and 3). Hypothesis $\mathrm{H} 2$ is thus supported by this exploratory study. Although the three change readiness activities are of a different nature, requiring specific attention and capabilities, the study confirmed hypothesis $\mathrm{H} 1$ that the three are correlated. The exception is the insignificant correlation of the innovative action variable, associated with the trigger of threat or opportunity, with the early identification variable of the other type of trigger. All other hypothesized correlations between the three response variables, separately for threats and for opportunities, are empirically supported. The implication is that it is possible to classify organizations on the basis of their combined patterns of response to threats and opportunities.

The study found a limited correlation between response to threats and response to opportunities. The early identification and the mobilization for action variables are correlated, but the innovative action dealing with threats are not correlated with the innovative action dealing with opportunities (see Table 2). Apparently the notion of identifying trends and acting quickly to deal with them is an organizational capability. But the nature of the response is specific and separate in dealing with threats versus dealing with opportunities.

The study confirmed hypotheses $\mathrm{H} 3$ that, by and large, organizations tend to identify opportunities earlier than threat, to act faster in preparing to deal with opportunities and to develop more innovative solutions. Possible explanation for this finding is the human and managerial tendency to look at the positive side of events and to hesitate about reporting and acting on negative developments. High organizational inertia and wishful thinking could be more common in dealing with fears.

The finding supports hypothesis $\mathrm{H} 4$ that whether organizations give priority to dealing with threat or with opportunities depend on their orientation and strategy. Some organizations are more likely, in view of their position 
and past achievements, to concentrate on defending what they have got. Other firms are more eager to expand and take advantage of opportunities either because they need to grow and develop in order to be more profitable, or because they are in an industry in which taking advantage of opportunities is a key to long term survival. It is possible that other organizational characteristics are associated with different response patterns. Personality of the leaders could also play a role in the priority given to threats versus opportunities.

\section{Conclusion}

In the highly dynamic, and turbulent global markets of today, major threats and opportunities are quite common. The paper suggests that dealing successfully with these developments could be based on organizing for three distinct activities which were suggested to mean change readiness. These are: Environmental rigger identification, quick mobilization in preparing for change and newness in the content of response. High performance on these variables has been shown to be correlated and possible predictors of success in dealing with major threats and opportunities.

A second part of the study explored the priority that organizations give to dealing with threat versus dealing with opportunity. It was interesting to find a bias in favor of opportunities rather than threats. This is in contrast with the expectation that individuals are more concerned with loss than with gain. A possible explanation is the difference between an individual response and a manager's response. The manager is acting in a framework of organizational life where messengers of bad news are frequently not in favor. The clear implication for top management is to encourage change readiness of threats as well as opportunities and be careful of the way the organization treat managers with information and plans related to threats.

The study finds that change readiness is stronger for threats, in comparison with opportunities, for organizations that are more defensive and internally oriented. The opposite is true for externally and expansion oriented firms. The finding makes sense and could be part of an explicit strategy. It is useful to be aware of the bias and make sure that it is consistent with the firm goals.

The study is called exploratory as it has some important limitations. For most firms there was only one responding manager from each organization, the response to the questions were subjective and the threats and opportunities were self-selected and not specified. The sample selection was convenient. There could be a question about the direction of causality if managers report on the change readiness variables based on the degree of successful treatment. Omitted explanatory and organizational variables introduce additional uncertainties.

Nevertheless, the correlation models performed quite well and with a reasonable degree of stability. Further studies can attempt to include a larger and possibly more representative sample of organizations with more respondents from each. An attempt could be made to assess success in a more objective way. Separate model development and analysis could take into account type of industry and organization, executive characteristics and a classification of threats and opportunities.

\section{References}

Aaker, D. A., \& Mascarenhas, B. (1984). The Need for Strategic Flexibility, Journal of Business Strategy, 5(2), 74-82. http://dx.doi.org/10.1108/eb039060

Ansoff, H. I. (1965). Corporate Strategy. McGraw-Hill, New York.

Ansoff, H. I. (1984). Implanting Strategic Management. Prentice-Hall, New Jersey.

Ansoff, H. I. (1988). The New Corporate Strategy. John Wiley \& Sons, New York.

Chattopadhyay, F., Glick, W. H., \& Huber, G. P. (2001). Organizational Action in Response to Threats and Opportunities. Academy of Management Journal, 44(5), 937-955. http://dx.doi.org/10.2307/3069439

Kahanman, D., \& Tversky, A. (1979). Prospect Theory: An Analysis of Decision Under Risk. Econometrica, 47, 263-292. http://dx.doi.org/10.2307/1914185

Kotter, J. P. (2008). A Sense of Urgency. Harvard Business Press, Boston.

Mitroff, Ian I. (1988). Break-Away Thinking. John Wiley and Sons, New York, pp. 30-31.

Segev, E., \& Gray, P. (1990). Business SUCCESS. Prentice Hall, New Jersey.

Timmor, Y., \& Zif, J. (2010). Change Readiness: An Alternative Conceptual and Empirical Examination. Euro Med Journal of Business, 5(2), 138-165. http://dx.doi.org/10.1108/14502191011065482

Urban, Glen L., \& Steven, H. Star. (1991). Advanced Marketing Strategy. Prentice Hall, New Jersey, pp. 288-289. 